\title{
Modeling and Control Strategy for Variable Speed Wind Turbine Using Permanent Magnet Synchronous Generator
}

\author{
Shafiul Hasan Rafi*, Rusnot Ara Ferdous and M.R.I. Sheikh \\ Dept. of Electrical, Electronic and Communication Engineering, MIST, Dhaka, \\ Bangladesh.
}

*Corresponding Author E-mail: shafiul.hasan1991@gmail.com

\begin{abstract}
This paper proposes an optimized model and control strategy for variable speed wind turbine using permanent magnet synchronous generator (PMSG). Models and equations that describe different components of the wind energy conversion system (WECS) are addressed and their implementations into PSCAD/EMTDC are described. There are different types of synchronous generators, but the PMSG is chosen. It offers better performance due to higher efficiency and less maintenance since it does not need external DC source and can be used without a gearbox, which also implies a reduction of the weight of the nacelle and a reduction of costs. For the better performance, in this model two level IGBT converter and three level IGBT inverter set has been used associated with the maximum power point tracking (MPPT) system.Simulation results show that the controllers can extract maximum power and regulate the voltage and frequency under varying wind and load conditions. The controller shows very good dynamic, steady state and transient performance.
\end{abstract}

Keywords: Wind Turbine, Modelling, PMSG, Control Strategy, WECS.

\section{INTRODUCTION}

PMSG based variable speed wind turbine are mostly concentrated on the DC to AC inversion process using 2-level IGBT inverter [3, 4, 5]. Much attention has not been paid for a DC to AC inversion system using multilevel IGBT inverter $[4,5,6]$. In this model two level AC to DC converter, a DC link capacitor and three level DC to AC inverter are used. It is seen that proposed model perform better than conventional one, and can be used both in dynamic and transient condition

Wind is a promising source of renewable energy. Over recent years, a new scheme for wind generators has become popular which includes a variable speed wind turbine with permanent magnet synchronous generator (VSWT-PMSG). Direct-drive PMSG raises great interest because of its high efficiency and elimination of the gearbox [1]. PMSG has received much attention in wind energy application because of their property of selfexcitation, which allows an operation at a high power factor and high efficiency.Usually, a PMSG-based wind energy conversion system (WECS) is composed of mechanical, electrical and control subsystems whose time constants vary from microseconds to minutes or even more [2].This paper deals with the detailed study of dynamic stability as well as transient stability of WECS based on PMSG. Due to the recent development in power electronics and control system have made it possible to regulate the grid side voltage, real power and reactive power of PMSG in many different ways. PMSG is directly driven by a wind turbine without gear-box and it is connected to the AC power 
grid through power converters. In the recent years, some works have been done on PMSG based wind farm. Previous publications related to

\section{MODELING OF THE WIND TURBINE}

The main parts of the gearless WECS are the wind-turbine, the permanent magnet synchronous generator, the back to back converters with their control, and the pitch controller [7]. A 3MW direct drive wind turbine (WT) unit is considered for this analysis.

\section{A. Wind Turbine}

According to the blade element theory [8], modeling of blade and shaft needs complicated and lengthy computations. Moreover, it also needs detailed and accurate behavior of the system, a simplified method of modeling of the wind turbine blade and shaft is normally used [9]. The mathematical relation for mechanical power extraction from the wind can be expressed as follows [8].

$$
P_{m=} \frac{1}{2} \rho \pi R^{2} V_{w}^{3} C_{p}(\lambda, \beta)
$$

Where, $P_{m}$ is the mechanical power, $\rho$ is the air $\operatorname{density}\left(\mathrm{Kg} / \mathrm{m}^{3}\right)$, $\mathrm{R}$ is the blade radius (m), $C_{p}$ is the power coefficient, $\lambda$ is the tip speed ratio, $\beta$ is the blade pitch angle (deg), Tip speed ratio $\lambda$ can be expressed as [3]

$$
\lambda=\frac{\omega R}{V_{w}}
$$

Where $\omega$ is the turbine angular speed $(\mathrm{rad} / \mathrm{s}), V_{w}$ is the wind speed $(\mathrm{m} / \mathrm{s})$.

Power coefficient, $C_{p}$ is, [10]

$$
C_{p}=\frac{1}{2}\left(\Gamma-.022 \beta^{2}-5.6\right) e^{-0.1 \Gamma}
$$

Where, $C_{p}$ expressed in feet and mile, $\lambda$ is corrected as

$$
\Gamma=\left(\frac{R}{\lambda}\right) *\left(\frac{3600}{1609}\right)
$$

The torque coefficient, is given by

$$
C_{T}=\frac{C_{p(\lambda)}}{\lambda}
$$

The wind torque is expressed as

$$
T_{m}=\frac{1}{2} \rho \pi R^{3} V_{w}^{2} C_{T}(\lambda)
$$

The $C_{p}-\lambda$ characteristics, for different values of pitch angle are shown in the Fig. 1

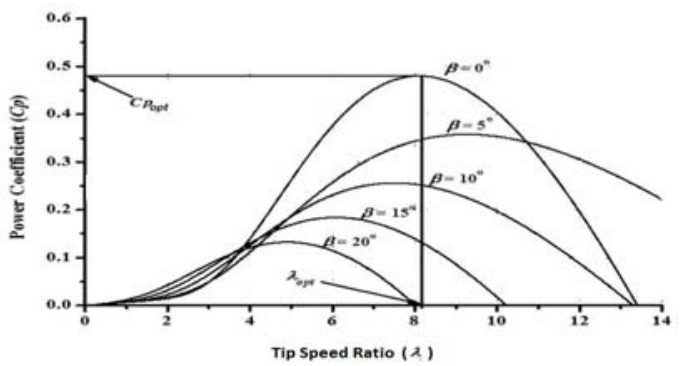

Fig. 1: $C_{p}-\lambda$ characteristics for different pitch angle, $\beta$ 
From the different values of pitch angle, we can obtain maximum value of $C_{p}$ i.e. $C_{p_{\text {opt }}}=0.48$ for $\beta=0$ and for $\lambda=8.1, \lambda$ is defined as the optimal value, $\lambda_{\text {opt }}$.

\section{PMSG Model}

The dynamic model of the PMSG is derived from the two-phase synchronous reference frame, which the q-axis is 90 degree ahead of the d-axis with respect to the direction of rotation. The synchronization between the $\mathrm{d}-\mathrm{q}$ rotating reference frame and the abc-three phase frame is maintained by utilizing a phase locked loop [4].The park model of PMSG is given in the Fig. 2 [10].

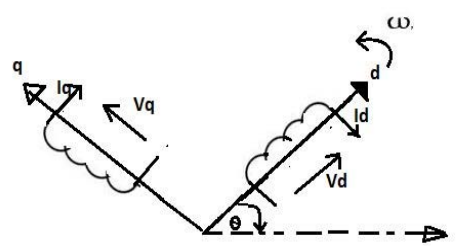

Fig. 2: Park model of PMSG

The sinusoidal distribution of conductors and flux are the linear function of currents situated on the rotor. They are given by the equations [12]

$$
\begin{gathered}
\Psi_{d}=L_{d} i_{d}+\Psi_{f} \\
\Psi_{q}=L_{q} i_{q}
\end{gathered}
$$

Where, $L_{d}$ is the stator inductance in d-axis, $L_{q}$ is the stator inductance in q-axis, $\Psi_{f}$ is the magnetic flux.

The equations for modeling PMSG are given by [11]

$$
\begin{gathered}
\frac{d i_{d}}{d t}=\frac{1}{L_{d}}\left[v_{d}+p \omega_{g} L_{q} i_{q}-R_{d} i_{d}\right] \\
\frac{d i_{q}}{d t}=\frac{1}{L_{q}}\left[v_{q}-p \omega_{g}\left(L_{d} i_{d}+M i_{f)}-R_{q} i_{q}\right]\right.
\end{gathered}
$$

Where, $i_{d}$ are stator currents, $v_{d}$ are the stator voltages, $p$ is the number of pair of poles. $R_{d}, R_{q}$ are the stator resistances, Mis the mutual inductance, $i_{f}$ is the equivalent rotor current, $\omega_{g}$ is the rotor angular speed.

The electrical rotating speed of the generator is $\omega_{e}$ which is expressed as [4]:

$$
\omega_{e}=p \times \omega_{g}
$$

Where, $p$ is the number of pole pair generator. 
The electromagnetic torque can be expressed as [12]:

\section{Control Strategy OF PMSG}

The control strategy of VSWT-PMSG is divided in two parts, the generator side control system and grid side control system. The generator is connected to the grid through a full scale back to back power converter linked by a DC bus. In this modified proposed model, the generator side converter is a standard three phase two-level unit, composed of six insulated gate bipolar junction transistors (IGBTs) and anti parallel diodes. On the other hand, the grid side inverter is a standard three-level unit, composed of twelve IGBTs and anti parallel diodes. The three phase AC output of the generator is rectified through a converter and the rectified DC output is fed to an IGBT based grid side inverter. Its output is fed to the step-up Transformer and then to the grid. The whole control strategy of the VSWT-PMSG is shown in the Fig. 3.

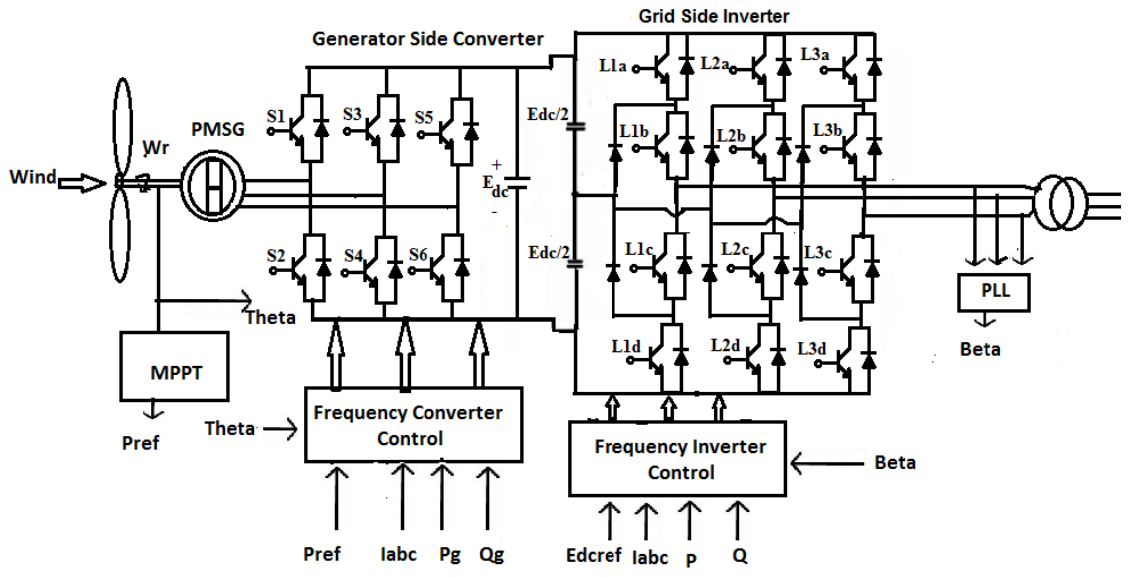

Fig. 3: Electrical scheme of VSWT-PMSG

\section{CoNTrol STRATEgy OF FrequenCy CONVERTER-INVERTER SET}

\section{A. Generator Side Frequency Converter}

The structure of the control strategy of the frequency converter is shown in the Fig. 4 . The control signal applied to the IGBT's gate switching is three phase sinusoidal voltage which is derived from the $d-q$ axis signal. 
Magnet Synchronous Generator

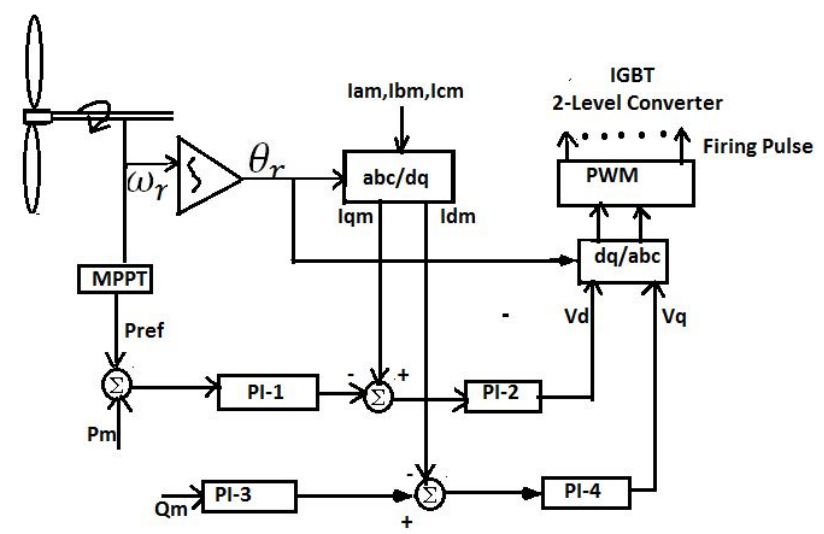

Fig. 4: Control structure for generator side frequency converter

\section{B. Grid Side Frequency Inverter}

The grid side inverter control the DC link capacitor voltage at the set value, so that the active power can be exchanged efficiently from PMSG to the grid. It also controls the reactive power output to the grid in order to control the grid side voltage. In this control strategy, d-axis of reference frame is oriented along the grid voltage. Therefore active and reactive power can be expressed as [13]:

$$
\begin{gathered}
P_{\text {grid }}=\left(v_{d_{\text {grid }}}\right) *\left(I_{d_{\text {grid }}}\right) \\
Q_{\text {grid }}=-\left(V_{d_{\text {grid }}}\right) *\left(I_{d_{\text {grid }}}\right)
\end{gathered}
$$

The proposed Control structure of the Grid side frequency inverter is shown in the Fig. 5.

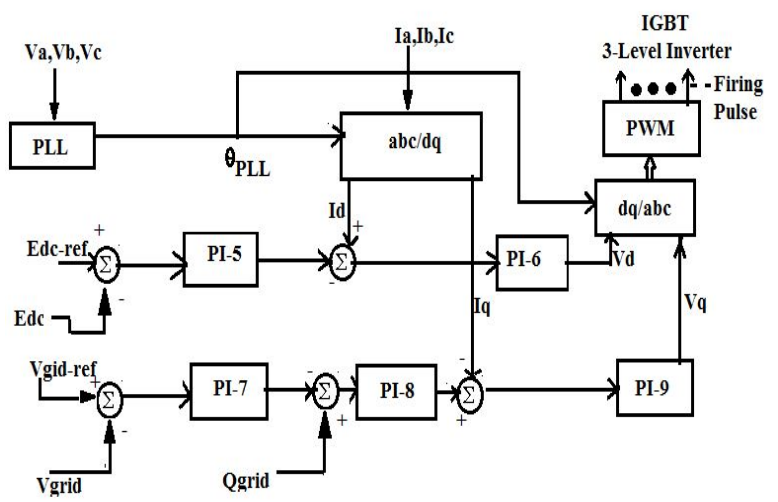

Fig. 5: Control structure for grid side frequency inverter 


\section{Proposed PWM Control for 3-level Frequency Inverter.}

This thesis work focuses on the analysis of a three-level inverter. Three-level inverters have compared to two level inverters isminimum harmonic distortion and desirable voltage and frequency have been achieved.

The standard three-phase 3-level inverter has twelve switches which switching depends on the modulation scheme. The triangular signal is used as a carrier wave of pulse widthModulation (PWM) operation. The carrier frequency is chosen $1000 \mathrm{~Hz}$. The DC link capacitor is valued $5000 \mathrm{mF}$. The rated DC link voltage is $1 \mathrm{pu}$. PWM technique has been used in this three-phase 3 level inverter, in which three sine waves ( $\mathrm{Va}, \mathrm{Vb}, \mathrm{Vc})$ phase shifted by $120^{\circ}$ with the frequency of the desired output voltage is compared with a very high frequency $(1000 \mathrm{~Hz})$ carrier triangle, the two signals are mixed in a comparator whose output is high when the sine wave is greater than the triangle and the comparator output is low when the sine wave or typically called the modulation signal is smaller than the triangle. The Switching pulse generator of the IGBT-3-level inverter is shown in the Fig. 6.

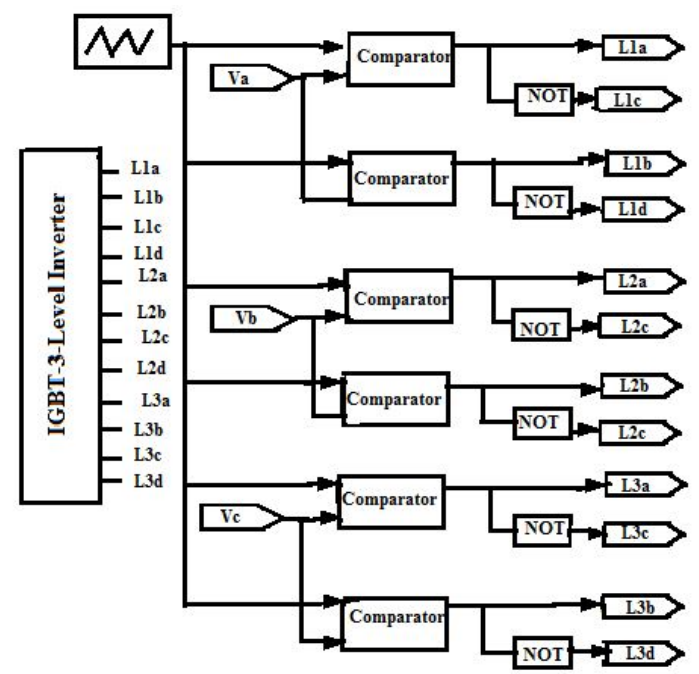

Fig. 6: Switching pulse generator of the IGBT-3-level inverter

\section{SIMULATION RESULTS}

Simulations were run in power systems computer aided design/electromagnetic transient including DC (PSCAD/EMTDC), for $300 \mathrm{sec}$ with natural wind speed data. The timing step of the simulation is chosen to be $0.001 \mathrm{sec}$. The simulation results are based on the dynamic behavior as well as transient behavior of the VSWT-PMSG during wind speed changes. All the simulation results are compared with the conventional model of VSWTPMSG and show the improvement response of the proposed PMSG based wind farm scheme. Here two cases of stabilities have been considered to verify the effectiveness of the proposed PMSG based wind farm model. 


\section{Case [1]: Dynamic Stability}

Fig. 7 shows the natural wind speed data used for the simulation study, for duration of 300sec. The response of the mechanical rotor speed of the modified model of VSWTPMSG is shown in Fig. 8 which is compared with the conventional model where it can be observed that the rotor speed varies as the nature of the wind speed captured. Fig. 9 illustrates the real power, $\mathrm{P}$, available at the grid side. With varying wind speed, the response of the real power obtained from the modified model is far better than the conventional model and maintains a constant desired value. Similar result can be observed in Fig. 10, in case of reactive power, Q, at the grid side. Fig. 11 shows the terminal voltage generated by the VSWT-PMSG from the variable wind speed input to the wind turbine. It can be seen that despite the variable nature of the wind energy, the terminal voltage generated by the generator remains constant. Fig. 12 shows the frequency response at the grid side which remains almost constant under the same wind speed data. From this Figure, it can be seen that modified model frequency response is much better than the conventional model over a same time period.

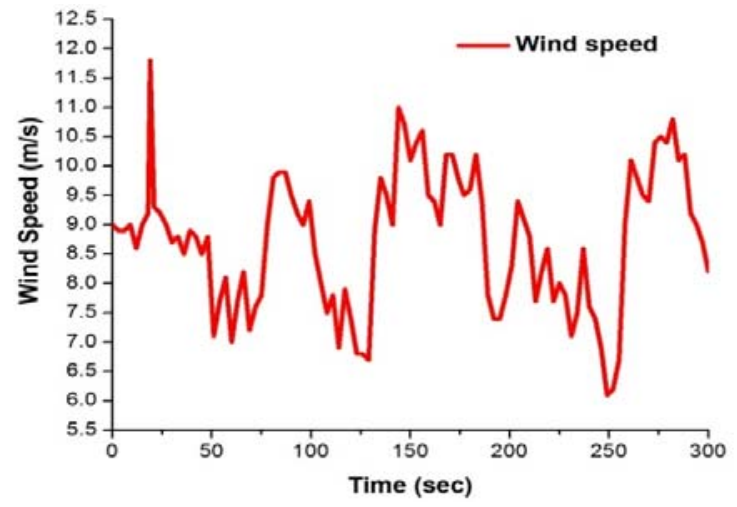

Fig. 7: Wind speed data

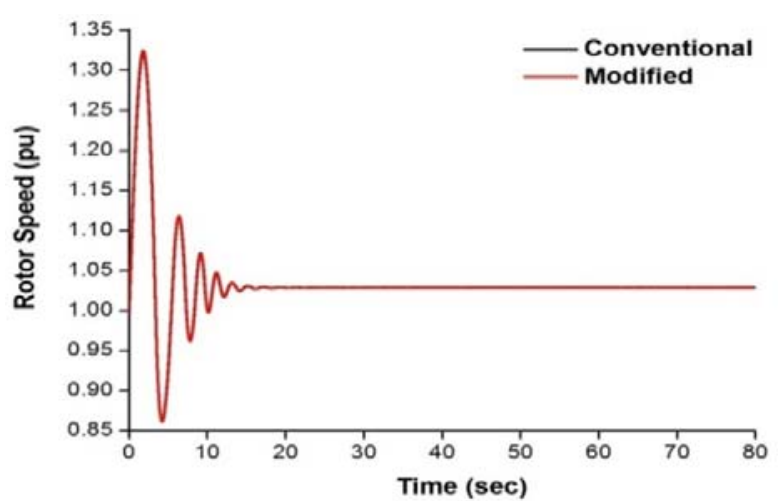

Fig. 8: Rotor speed (pu) 


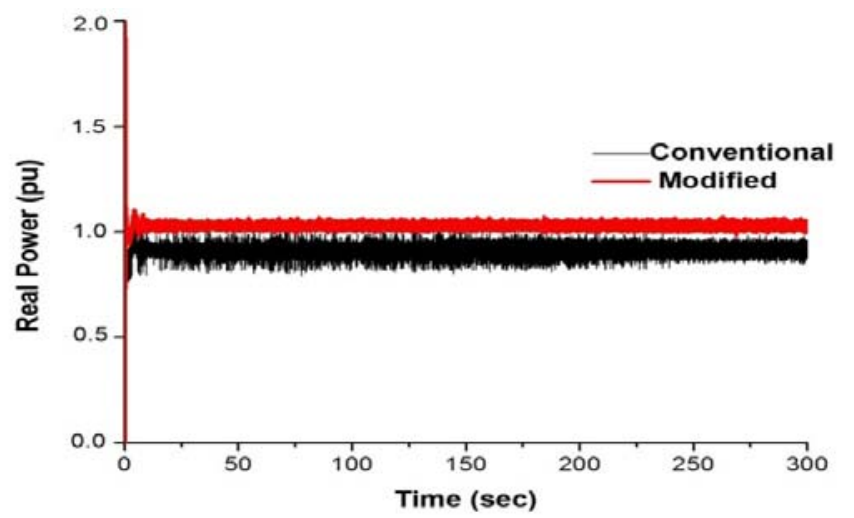

Fig. 9: Real power (pu)

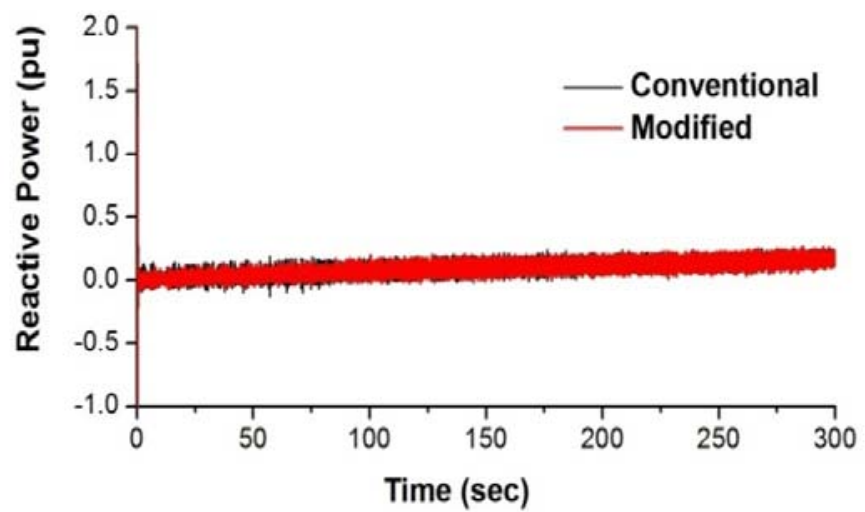

Fig. 10: Reactive power (pu)

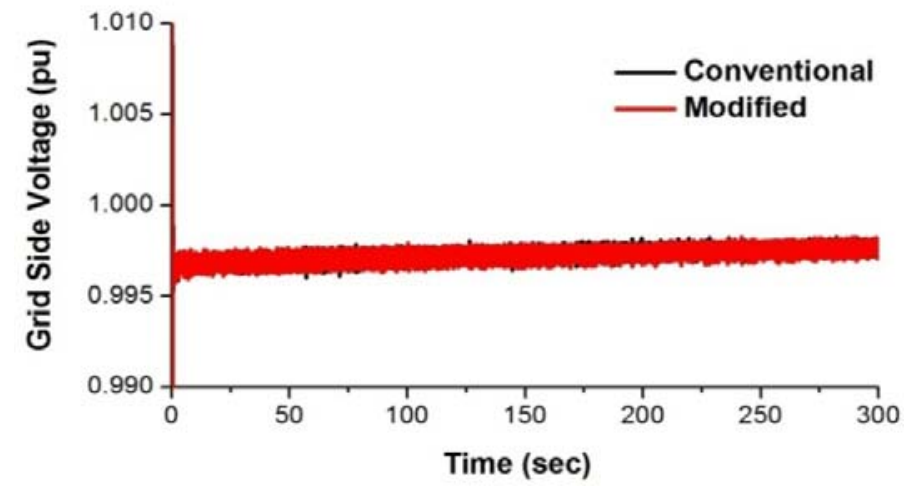

Fig. 11: Grid side voltage (pu) 


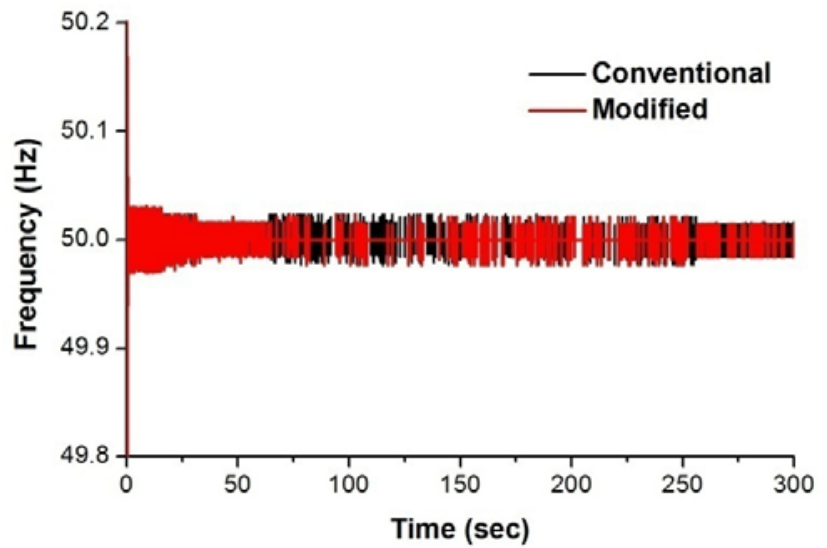

Fig. 12: Frequency response

\section{Case [2]: Transient Stability}

For transient stability analysis wind speed is assumed constant because the time duration of fault is very small. In this study the dynamic wind speed data shown in Fig.7 is used to make the proposed modified system more practical. For determining transient stability, three line to ground fault (3LG) has been considered. Time to apply fault is at 0 sec and the duration of the fault is .05s so that it is cleared within .05s. Simulations have been done by using PSCAD/EMDC [14] program for $300 \mathrm{sec}$ with the timing step of .001sec.

Fig. 13 shows the rotor speed variation of PMSG during fault. Just after clearing the fault, rotor speed return back to the normal state.

In Fig. 14, Real power available at the grid side is shown during fault at 0 sec. After clearing the fault, it returns back to the normal state as soon as possible. The proposed model response time during fault is better than the conventional model which is observed from the Fig. 14. Similar response can be obtained for the Reactive Power in the Fig. 15.

The grid side voltage is shown in the Fig. 16 which maintains the rated voltage after clearing the fault.

Fig. 17 represents the transient response of the frequency. Transient stability of the frequency response of the proposed model is very quicker than the conventional model during the fault.

Fig. 18 represents the per unit transient response of the DC link voltage after the generator side AC/DC converter during fault. 


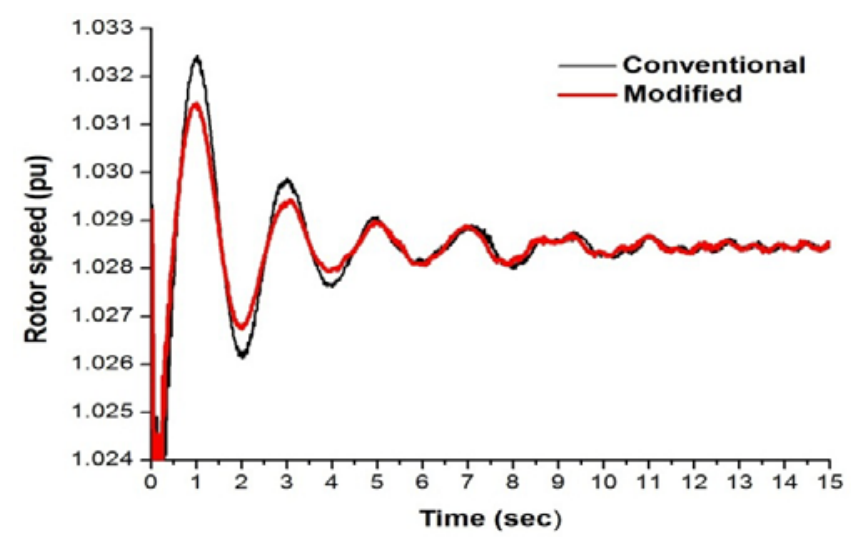

Fig. 13: Rotor speed (pu) during fault

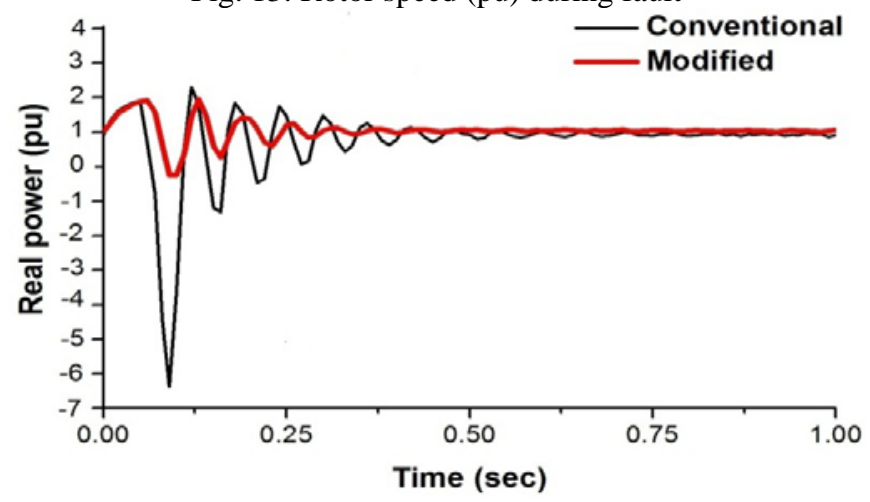

Fig. 14: Real power (pu) at the grid during fault

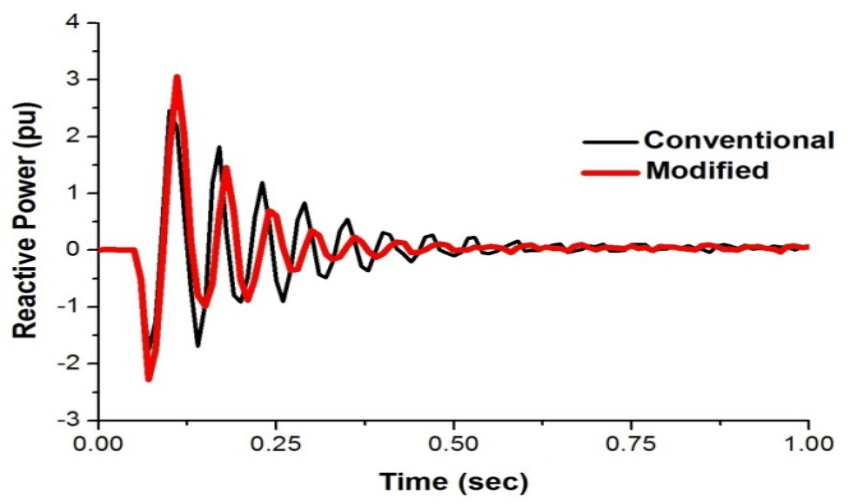

Fig. 15: Reactive power (pu) during fault 


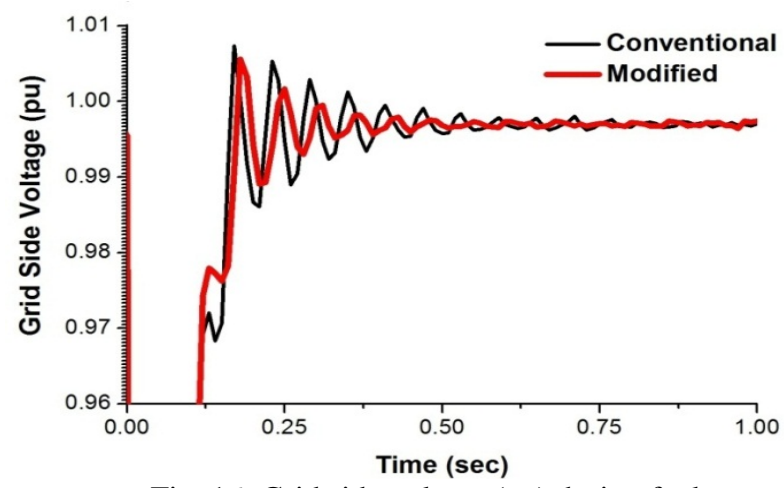

Fig. 16: Grid side voltage (pu) during fault

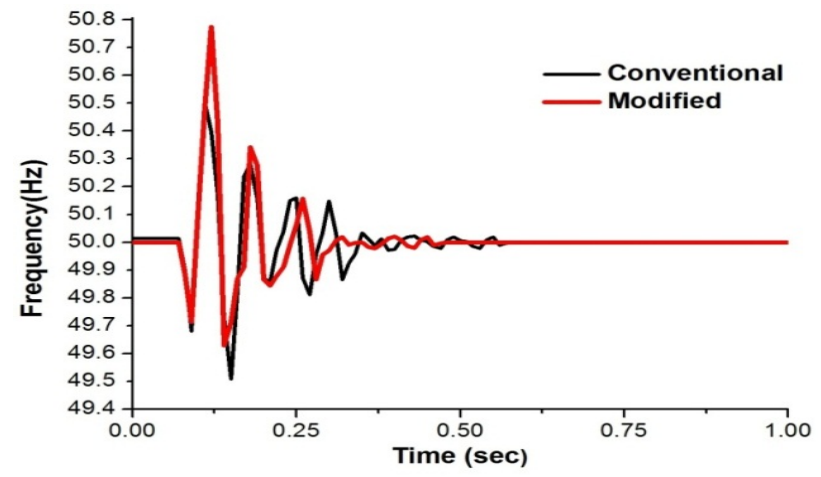

Fig. 17: Frequency response (Hz) during fault

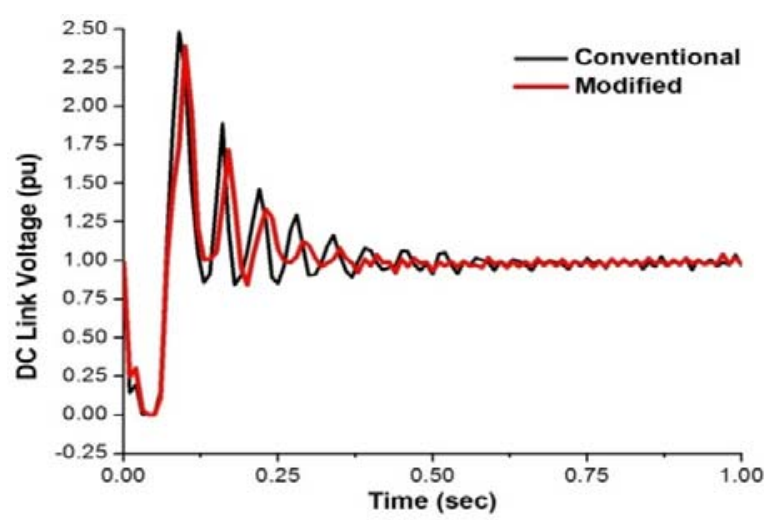

Fig. 18: DC link voltage (pu) during fault 


\section{CONCLUSION}

In this thesis, the modeling and control design of the variable speed wind turbine (VSWT) driven by a permanent magnetic synchronous generator (PMSG) is presented. The modeling of the wind turbine is also described. The modeling and control strategy for the grid side 3-level frequency inverter is presented. Control strategies are suitable for improving dynamic as well as transient stability. It isseen that the proposed model has better capability of dynamic response with compared to conventional model. At the same time, the proposed model is more capable to responding to a fault and return back to the normal state within a short time. Thesimulation results demonstrate that the controller works verywell and shows very good dynamic and transient response.

\section{References}

[1] H. Polinder, F. van der Pijl, G.-J. de Vilder, and P. Tavner,“Comparison of direct-drive and geared generator concept for wind turbines,” IEEE Transactions on Energy Conversion, vol. 21, no. 3, pp. 725-733, Sept. 2006.

[2] Engineering, 2013, 5, 96-100 doi:10.4236/eng.2013.51b017 Published Online January 2013 (http://www.SciRP.org/journal/eng)

[3] IEEE International Symposium on Industrial Electronics (ISIE 2009) Seoul Olympic Parktel, Seoul, Korea July 5-8, 2009

[4] S.Vijayalakshmi et al. / International Journal of Engineering Science and Technology (IJEST) /ISSN : 0975-5462 Vol. 3 No. 3 March 2011

[5] International Conference on Renewable Energies and Power Quality (ICREPQ'12) Santiago de Compostela (Spain), 28th to 30th March, 2012

[6] Okedu, K.E. 2011. "Wind Turbine Driven by Permanent Magnetic Synchronous Generator”. Pacific Journal of Science and Technology. 12(2):168-175.

[7] Jordan Journal of Mechanical and Industrial Engineering/Volume 5, Number 6, Dec. 2011/ ISSN 1995-6665,Pages 489 - 494

[8] S. Heier, Grid Integration of Wind Energy Conversion System, John Wiley and Sons Ltd., (1998)

[9] M.R.I. Seikh, S.M Muyeen,R. Takahashi, T.Murata, and J.Tamura, International Review of Automatic Control(IEACO), 1(3), 311(2008). Doi:10.1541/ieeejpes.126.742

[10] Muyeen, S.M, J. Tamura, and T. Murata. 2009. Stability augmenttation Grid-connected Wind Farm. $1^{\text {St }}$ Eidition. Green energy and Technology, Springer-Verlag: London, UK

[11] http://www.intechopen.com/books/wind-turbines/wind-turbines-with-permanent-magnetsynchronous-generator-and-full-power-converters-modelling-control

[12] Jordan Journal of Mechanical and Industrial Engineering/Volume 5, Number 6, Dec. 2011/ ISSN 1995-6665,Pages 489 - 494

[13] L.M. Fernandes, C.A Garcia, F.Jurado, “Operating Capability as a PQ/PV node of a DirectDrive Wind Turbine based on permanent magnet synchronous generator." Journal of Renewable Energy, Vol. 35,pp.1308-1318, 2010

[14] “PSCAD/EMTDC Manual,” Manitoba HVDC Research Center, 1994. 